\title{
PENGEMBANGAN PERANGKAT PEMBELAJARAN IPA DENGAN STRATEGI PREDICT-DISCUS-EXPLAIN- OBSERVE-DISCUS-EXPLAIN (PDEODE) UNTUK MEMINIMALISASI MISKONSEPSI SISWA SMP
}

\author{
Megawati' $^{1)}$, Muslimin Ibrahim ${ }^{2}$, Tjipto Haryono ${ }^{3)}$ \\ ${ }^{1)}$ Program Studi Pendidikan Sains, Program Pascasarjana Universitas Negeri Surabaya, \\ ${ }^{2)}$ Dosen Program Studi Pendidikan Sains, Program Pascasarjana Universitas Negeri Surabaya \\ ${ }^{3)}$ Dosen Program Studi Pendidikan Sains, Program Pascasarjana Universitas Negeri Surabaya \\ e-mail: mega.jilc@gmail.com
}

\begin{abstract}
Abstrak: Penelitian ini bertujuan mengembangkan perangkat pembelajaran IPA berbasis PDEODE untuk meminimalisasi miskonsepsi siswa SMP pada materi struktur dan fungsi jaringan tumbuhan. Perangkat pembelajaran dikembangkan menggunakan model 4-D. dengan desain uji coba one group pretest-postest design. Perangkat pembelajaran diujicoba pada 25 siswa Kelas VIII-B SMP Raden Rahmat Surabaya semester gasal tahun ajaran 2016/2017. Pengumpulan data dilakukan dengan menggunakan teknik validasi, observasi, tes, dan angket. Data penelitian dianalisis secara deskriptif kuantitatif dan kualitatif. Temuan hasil penelitian, yaitu: (1) Validitas perangkat meliputi Rencana Pelaksanaan Pembelajaran (RPP), Buku Ajar Siswa (BAS), Lembar Kegiatan Siswa (LKS), dan instrumen tes identifikasi miskonsepsi.dinyatakan valid; (2) Kepraktisan perangkat pembelajaran diperoleh dari: (a) keterlaksanaan RPP berkategori sangat baik, (b) aktivitas siswa; dan (3) Keefektifan perangkat pembelajaran ditinjau dari: (a) penurunan miskonsepsi siswa dari tes awal ke tes akhir, (b) ketuntasan hasil belajar kognitif, dan (c) respon siswa. Berdasarkan hasil analisis data, dapat disimpulkan bahwa perangkat pembelajaran IPA berbasis strategi PDEODE yang dikembangkan layak untuk meminimalisasi miskonsepsi IPA siswa SMP
\end{abstract}

Kata Kunci: Pengembangan Perangkat Pembelajaran, PDEODE, Minimalisasi Miskonsepsi, Certainty of Response Index (CRI)

\begin{abstract}
Abstract: This research had aimed to develop a Natural Science Learning Material with PDEODE strategy to minimize misconceptions of Junior High School students on material structure and function of plant tissue. The learning instrument is developed by using 4-D model with a try out-design namely one group pre-test - post-test design. The lesson plan has been tried out to 25 students' of VIII-B class SMP Raden Rahmat Surabaya in the odd semester of 2016/2017 academic year. The data collection apply data validation, observation, achievement test, and questionnaire. The research data were analysed descriptively both qualitative and quantitative. The research findings were as follows: (1) The validity of the learning instrument which comprises Lesson Plan, Student Book, Student Worksheet, and a valid Identify Misconceptions Instrument; (2) The practicality of the learning instrument that can be found from: (a) the implementation of the lesson plans that is categorized as 'good', (b) the students' activities and (3) The effectiveness of the learning instrument that was reviewed through: (a) the decrease misconception student from pretest to postest;; and (b) the response of students'. Based on the data analysis, it can be concluded that the Natural Science Learning Instrument based Predict-Discuss-Explain Observe-Discuss-Explain (PDEODE) strategy was feasible to minimize of misconceptions student's Junior High School.
\end{abstract}

Keywords: Development Learning Material, PDEODE, Minimize of Misconceptions, Certainty of Response Index $(C R I)$. 


\section{PENDAHULUAN}

Peranan kemajuan ilmu pengetahuan dan teknologi yang semakin vital dalam kehidupan manusia saat ini menuntut kecakapan hidup sumber daya manusia yang sesuai agar dapat survive. Pada abad 21 ini perkembangan dunia informasi, pengetahuan dan teknologi mengalami perubahan yang sangat cepat, sehingga dibutuhkan sumber daya manusia yang berkualitas yang dapat merespon perubahan yang terjadi. Pendidikan dalam hal ini dilaksanakan dengan berbasis pada salah satu kebutuhan dasar bagi akselerasi kemajuan bangsa yakni kompetensi ilmu pengetahuan dan teknologi. Implementasinya dalam pendidikan di Indonesia, standar nasional pendidikan menekankan pelaksanaan proses pembelajaran di sekolah dilaksanakan melalui proses pengonstruksian pengetahuan dan keterampilan yang berpusat pada siswa. Siswa difasilitasi melalui proses pembelajaran sehingga dapat secara aktif mengonstruksi pengetahuan dan keterampilan yang dipelajari. Hal ini berdasar pada tinjauan psikologis bahwa siswa sebagai individu pada hakikatnya mempunyai potensi untuk mencari dan mengembangkan dirinya. Pembelajaran menciptakan lingkungan yang menunjang bagi teraktualisasinya potensi siswa tersebut, dengan demikian pelaksanaan pembelajaran perlu menciptakan situasi belajar yang dapat memberi stimulus bagi kreativitas siswa dalam mencari dan menemukan pengetahuan yang seharusnya diperoleh (Awi, 2009).

Siswa datang ke sekolah tidak dengan pikiran kosong, akan tetapi mereka memiliki beberapa ide sebelum datang sekolah. Siswa mungkin memiliki beberapa alternatif konsepsi dan konsep-konsep ilmiah yang diperoleh di sekitarnya. Costu (2008), mengemukakan bahwa siswa memasuki kelas untuk belajar sains dengan berbekal konsepsi alternatif dan konsepsi sains yang terbentuk dari pengalaman hidup sehari-hari. Konsepsi alternatif dalam ilmu pengetahuan bisa berasal dari sumber yang berbeda, seperti pengalaman sekolah, praktek sosial, pengalaman kehidupan sehari-hari, pengajaran, pengetahuan sebelumnya, guru, interaksi teman sebaya, dan buku pelajaran. Ketika siswa memperoleh suatu penjelasan terkait peristiwa sains, siswa dikatakan telah memiliki konsepsi alternatif. Konsepsi alternatif yang tidak bersesuaian dengan kesepakatan sains inilah yang dapat menjadi sumber terjadinya miskonsepsi (Niaz, 2012).

Membahas mengenai miskonsepsi, terlebih dahulu perlu diketahui tentang pengertian konsep. Menurut Soedjadi (1990) dalam Ibrahim (2012), definisi konsep sebagai ide abstrak yang digunakan untuk mengadakan klasifikasi atau penggolongan yang pada umumnya dinyatakan dengan suatu istilah atau rangkaian kata. Ibrahim (2012) mengemukakan konsep didefinisikan sebagai kumpulan stimulus (fakta, benda, peristiwa, dll) yang memiliki ciri sama (atribut). Atribut adalah ciri esensial yang membedakan contoh konsep dari yang bukan konsep. Menurut Suparno (2005), konsep awal yang siswa miliki terkadang bertentangan dengan konsep yang dikemukakan oleh para ahli, konsep yang tidak sesuai dengan konsep ilmiah itu biasanya disebut dengan miskonsepsi atau salah konsep. Bila suatu prakonsepsi tidak mudah berubah, dan orang memiliki prakonsepsi itu selalu kembali kepada prakonsepsinya sendiri meskipun telah diperkenalkan dengan konsep yang benar, hal itu dinamakan miskonsepsi (Ibrahim, 2012). Miskonsepsi merupakan salah satu masalah dalam pendidikan yang harus segera diselesaikan. Miskonsepsi siswa yang muncul terus menerus akan mengganggu pembentukan konsepsi ilmiah dan mengakibatkan masalah belajar yang dapat mempengaruhi hasil belajar siswa.

Menurut Ibrahim (2012), miskonsepsi yang dialami oleh siswa dapat terjadi karena berbagai hal seperti penguasaan konsep oleh siswa belum lengkap, sederhana, dan berbeda, ketidakmampuan siswa dalam membedakan atribut (ciri penentu) dari sejumlah ciri umum yang dimiliki oleh sebuah konsep, istilah seharihari yang dijumpai pertama kali oleh siswa di dalam bahasa ibunya, sumber belajar yang dig unakan oleh siswa untuk belajar konsep, dan latar belakang lingkungan siswa seperti budaya, bahasa yang digunakan, teman, saluran komunikasi dalam masyarakat (radio, televisi, film) yang menyampaikan informasi yang salah. Pengetahuan yang miskonsepsi jika dibiarkan akan berpengaruh terhadap proses penalaran, apabila siswa mengalami miskonsepsi, maka siswa akan kesulitan dalam mempelajari suatu konsep, dalam proses berpikir tentang konsep yang terjadi merupakan konsep-konsep yang salah, sehingga mengakibatkan menurunnnya kemampuan berpikir kritis. Untuk itu diperlukan perubahan pola pikir yang digunakan sebagai landasan pendidikan. Perubahan pola pembelajaran dari sekedar pemahaman menuju penerapan konsep dan prinsip keilmuan dengan memperhatikan pilar pendidikan yang dicanangkan UNESCO yaitu learning to know, learning to do, learning to live, dan learning to be (Depdiknas, 2003).

Teori pembelajaran konstruktivisme menyatakan bahwa siswa harus menemukan sendiri dan mentransformasikan informasi kompleks, mengecek informasi baru dengan aturan-aturan lama dan merevisinya apabila aturan-aturan itu tidak lagi sesuai. Untuk memahami dan menerapkan pengetahuan, siswa harus bekerja memecahkan masalah, menemukan 
segala sesuatu untuk dirinya, berusaha dengan susah payah dengan ide-ide tersebut (Trianto, 2009). Selain itu, menurut Kearney (2001) dalam jurnal Student and Teacher Perceptions of the Use of Multimedia Supported Predict-Observe-Explain Task to Probe Understanding, mengatakan bahwa, pembelajaran dalam pandangan konstruktivisme adalah suatu pembelajaran yang menuntut siswa untuk membangun suatu konsep berdasarkan pengalaman yang baru didapatkannya dan menghubungkannnya dengan pengalaman yang sudah ada sebelumnya.

Strategi yang dimaksudkan untuk diterapkan dalam penelitian ini adalah PDEODE. Strategi pembelajaran PDEODE pertama kali diusulkan oleh Svander-Ranne dan Kolari (Costu, 2008). Strategi pembelajaran PDEODE merupakan model pembelajaran yang mengkaitkan pengalaman kehidupan sehari-hari siswa dengan materi yang diajarkan. Strategi ini membantu siswa agar merasa seperti dalam situasi kesehariannya, dengan kondisi seperti itu siswa diberi kesempatan berinteraksi, sehingga meningkatkan intensitas interaksi antar siswa. Strategi PDEODE ini memiliki enam tahapan yaitu Predict (prediksi), Discuss I (diskusi), Explain I (menjelaskan), Observe (Pengamatan), Discuss II (diskusi) dan Explain II (menjelaskan) yang lebih rinci akan dijelaskan pada Bab II. Strategi ini dapat meminimalisasi miskonsepsi siswa karena: (1) siswa diberi kesempatan berdiskusi menyatukan keberagaman pandangan dalam menetapkan konsep baru yang sesuai dengan fakta, (2) siswa diberi kesempatan berinteraksi, sehingga meningkatkan intensitas interaksi antar siswa, (3) siswa dapat meramalkan apa yang akan terjadi, dan (4) sekaligus dapat membuktikannya lewat pengamatan langsung.

Hasil tes pra penelitian di SMP Raden Rahmat Surabaya yang menggunakan 35 sampel siswa menunjukkan bahwa dari 25 butir soal yang diberikan mengenai materi struktur dan fungsi tubuh tumbuhan, rata-rata siswa mengalami miskonsepi sebesar $57,2 \%$, tidak memahami konsep sebesar 14,3\%, dan memahami konsep sebesar 28,5\%. Hasil diskusi dengan guru IPA di sekolah tersebut diperoleh informasi bahwa selama ini materi struktur dan fungsi tubuh tumbuhan diajarkan hanya menyesuaikan dengan buku pelajaran dan alokasi waktu yang masih tersisa, sehingga apabila alokasi waktu telah habis maka siswa dipercayakan untuk belajar mandiri. Siswa tidak dihadapkan dengan fenomena atau peristiwa sains yang ada dalam kehidupan sehari-hari. Materi struktur dan fungsi tubuh tumbuhan sangat berperan penting dalam kehidupan sehari-hari siswa. Persentasi miskonsepsi yang dialami siswa pada materi tersebut cukup tinggi. Diperlukan pengetahuan baru yang benar agar pemahaman konseptual siswa pada materi struktur dan fungsi tubuh tumbuhan menjadi lebih baik.

Menurut penelitian yang dilakukan oleh Costu, (2008) menyatakan bahwa strategi PDEODE efektif dalam mereduksi miskonsepsi siswa pada materi IPA mengenai kondensasi. Begitu juga dengan penelitianpenelitian lain yang dilakukan oleh Gustiani (2013), Kearney (2001), Niaz (2012), Sa'idah (2012), Sekartini (2013), Solichah (2014), Suyati (2015), Tabitha (2012) bahwa pembelajaran dengan menggunakan strategi PDEODE dapat membangun suatu konsep, siswa dapat memahami dengan baik konsep tersebut sehingga efektif dalam mereduksi miskonsepsi siswa pada materi IPA.Berdasarkan latar belakang di atas, maka penulis akan melakukan penelitian tentang pengembangan perangkat pembelajaran IPA dengan strategi PDEODE untuk meminimalisasi miskonsepsi siswa SMP.

\section{METODE}

Penelitan ini termasuk penelitian pengembangan yang dilakukan dengan tujuan untuk mengembangkan perangkat pembelajaran meliputi: Rencana pelaksanaan pembelajaran (RPP), Buku Ajar Siswa (BAS), Lembar Kegiatan Siswa (LKS), dan Tes Identifikasi Miskonsepsi dengan menggunakan strategi PredictDiscus-Explain-Observe-Discus-Explain (PDEODE) untuk meminimalisasi miskonsepsi siswa SMP. Pengembangan perangkat pembelajaran yang digunakan mengacu pada model 4D (four D models), yang terdiri dari define, design, develop, dan desseminate (Thiagarajan, 1997 dalam Ibrahim dan Wahyusukartiningsih, 2014).

Rancangan penelitian yang dilakukan pada ujicoba I dan ujicoba II menggunakan one-group pretest-posttest design dengan menggunakan satu kelompok subjek dengan pola sebagai berikut:

\section{Keterangan :}

$$
\mathrm{O}_{1} \mathrm{X} \mathrm{O}_{2}
$$

$\mathrm{O}_{1}$ : Pretest (uji awal), sebelum pemberian perlakuan.

$\mathrm{X}:=$ Treatment, pemberian perlakuan dengan penerapan model inkuiri terbimbing.

$\mathrm{O}_{2}$ : Posttest (uji akhir), setelah pemberian perlakuan.

Variabel-variabel penelitian yang diamati dalam penelitian ini meliputi validitas perangkat, keterlaksanaan pembelajaran, pergeseran konsepsi siswa, dan respon siswa.

1. Analisis Validitas Perangkat Pembelajaran

Penilaian validitas perangkat pembelajaran ditentukan dengan menghitung rata-rata skor penilaian yang diberikan oleh dua orang validator. Skor penilaian menggunakan skala Likert dengan nilai skor 1-4. Skor 4 diberikan jika aspek yang dinilai pada lembar validasi baik. Skor 3 diberikan jika aspek yang dinilai 
pada

\begin{tabular}{rc}
\hline Kriteria & Penafsiran \\
\hline $\mathbf{1 \%}-\mathbf{2 0 \%}$ & Sangat kurang \\
$\mathbf{2 1 \%}-\mathbf{4 0} \%$ & Kurang \\
$\mathbf{4 1 \%}-\mathbf{6 0 \%}$ & Cukup \\
$\mathbf{6 1 \%}-\mathbf{8 0 \%}$ & Baik \\
$\mathbf{8 1 \%}-\mathbf{1 0 0 \%}$ & Sangat Baik \\
\hline
\end{tabular}

lembar validasi cukup baik. Skor 2 diberikan jika aspek yang dinilai pada lembar validasi kurang baik dan skor 1 diberikan jika tidak melaksanakan aspek yang dituliskan dalam lembar validasi. Skor validasi yang diperoleh kemudian diberikan kriteria seperti pada Tabel 1 sebagai berikut :

Tabel 1. Kriteria Pengkategorian Lembar Penilaian

\begin{tabular}{ccl}
\hline Interval skor & Kategori & \multicolumn{1}{c}{ Keterangan } \\
\hline $\mathbf{1 , 0 0} \leq \mathrm{SVP} \leq \mathbf{1 , 5 9}$ & Tidak valid & $\begin{array}{l}\text { Tidak dapat digunakan } \\
\text { dan masih memerlukan } \\
\text { konsultasi }\end{array}$ \\
$\mathbf{1 , 6 0} \leq \mathbf{S V P} \leq \mathbf{2 , 5 9}$ & $\begin{array}{l}\text { Kurang } \\
\text { valid }\end{array}$ & $\begin{array}{l}\text { Dapat digunakan } \\
\text { dengan banyak revisi }\end{array}$ \\
$\mathbf{2 , 6 0} \leq \mathrm{SVP} \leq \mathbf{3 , 5 9}$ & Valid & $\begin{array}{l}\text { Dapat digunakan } \\
\text { dengan sedikit revisi }\end{array}$ \\
$\mathbf{3 , 6 0} \leq \mathrm{SVP} \leq \mathbf{4 , 0 0}$ & $\begin{array}{l}\text { Sangat } \\
\text { valid }\end{array}$ & $\begin{array}{l}\text { Dapat digunakan tanpa } \\
\text { revisi }\end{array}$ \\
\hline & (Ratumanan dan Laurens, 2011)
\end{tabular}

Selain itu dilakukan perhitungan percentage agreement (persentase kecocokan) antar dua validator tersebut. Untuk menentukan percentage agreement digunakan rumus sebagai berikut :

Percentage of agreement $=\left(1-\frac{A-B}{A+B}\right) \times 100 \%$

Keterangan :

A : Frekuensi terbesar

B : Frekuensi terkecil

Instrumen penilaian perangkat pembelajaran akan disetujui jika nilainya $\geq 75 \%$ (Borich, 1994).

2. Analisis Data Kepraktisan Perangkat Pembelajaran

a. Keterlaksanaan Pembelajaran

Penilaian keterlaksanaan pembelajaran (RPP) dilakukan dengan menggunakan lembar pengamatan keterlaksanaan RPP yang berisis langkah-langkah yang harus dilakukan guru. Analisis keterlaksanaan pembelajaran yang diamati melalui RPP yang dibuat oleh guru. Lembar pengamatan keterlaksanaan RPP dibuat dalam bentuk pilihan "Ya" dan "Tidak", kemudian akan diberikan skor 4, 3, 2, 1 berdasakan penilaian dua pengamat dan kriteria yang telah ditentukan.
Persentase keterlaksanaan RPP dapat diketahui menggunakan rumus sebagai berikut:

Keterlaksanaan RPP (\%) $=\frac{\sum \text { skor yang diperoleh }}{\sum \text { skor maksimal }} \times 100 \%$

Persentase yang diperoleh diinterpretasikan ke dalam kriteria yang dapat dilihat pada Tabel 2 sebagai berikut:

Tabel 2. Kriteria Interpretasi Skor

(Riduwan, 2003)

Selain itu dilakukan perhitungan percentage agreement (persentase kecocokan antar dua pengamat tersebut. Untuk menentukan percentage agreement digunakan rumus sebagai berikut :

$$
\text { Percentage agreement }=\left(1-\frac{\mathrm{A}-\mathrm{B}}{\mathrm{A}+\mathrm{B}}\right) \times 100 \%
$$

Keterangan :

A : Frekuensi terbesar

B : Frekuensi terkecil

Instrumen penilaian keterlaksanaan RPP akan disetujui jika nilainya $\geq 75 \%$ (Borich, 1994).

\section{b. Aktivitas Siswa}

Penilaian dilakukan oleh dua orang pengamat terhadap aktivitas siswa setiap kali tatap muka. Respon siswa diukur dengan deskriptif kualitatif dengan menggunakan rumus sebagai berikut :

$$
P=\frac{\sum \mathrm{R}}{\sum N} \times 100 \%
$$

Keterangan:

$\mathrm{P} \quad$ : persentase aktivitas siswa

$\sum \mathrm{R}$ : jumlah frekuensi kategori pengamatan

$\sum \mathrm{N}$ : jumlah frekuensi seluruh kategori pengamatan

3. Analisis Data Keefektifan Perangkat Pembelajaran

\section{a. Kompetensi Pengetahuan}

1) Analisis Miskonsepsi

Metode yang digunakan untuk mengidentifikasi miskonsepsi yaitu dengan metode CRI. Metode CRI merupakan teknik untuk mengukur miskonsepsi seseorang dengan cara mengukur tingkat kepastian atau keyakinan seseorang dalam menjawab setiap pertanyaan yang diberikan. Selain digunakan untuk mengidentifikasi miskonsepsi, CRI juga dapat membedakan antara siswa yang tahu konsep, tidak tahu konsep, dan miskonsepsi. Skala yang digunakan pada CRI berkisar antara 0-5 yaitu $0=$ totally guessed answer (hanya menebak), 1 = almost guess (hampir menebak), 2 = not sure (tidak yakin), $3=$ sure (yakin), $4=$ almost certain (hampir pasti), $5=$ certain (pasti benar) (Hasan, et al, 1999). 
Hasil analisis dengan CRI digunakan untuk membedakan siswa yang tahu konsep, tidak tahu konsep, dan miskonsepsi. Matrik hasil interpretasi CRI dapat dilihat pada Tabel 3.

Tabel 3. Interprestasi CRI

\begin{tabular}{|c|c|c|}
\hline $\begin{array}{l}\text { Kriteria } \\
\text { Jawaban }\end{array}$ & $\begin{array}{l}\text { Rata-rata CRI } \\
\text { Rendah }(<2,5)\end{array}$ & $\begin{array}{c}\text { Rata-rata CRI } \\
\text { Tinggi }(>2,5)\end{array}$ \\
\hline $\begin{array}{c}\text { Jawaban } \\
\text { Benar }\end{array}$ & 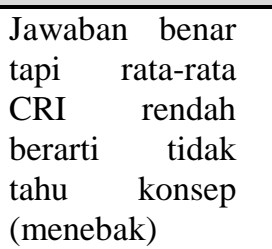 & $\begin{array}{l}\text { Jawaban benar } \\
\text { dan rata-rata CRI } \\
\text { tinggi berarti } \\
\text { menguasai } \\
\text { konsep dengan } \\
\text { baik }\end{array}$ \\
\hline $\begin{array}{c}\text { Jawaban } \\
\text { Salah }\end{array}$ & $\begin{array}{l}\text { Jawaban salah } \\
\text { dan rata-rata CRI } \\
\text { rendah berarti } \\
\text { tidak tahu konsep }\end{array}$ & $\begin{array}{l}\text { Jawaban salah } \\
\text { tapi rata-rata CRI } \\
\text { tinggi berarti } \\
\text { terjadi } \\
\text { miskonsepsi }\end{array}$ \\
\hline
\end{tabular}

(Hasan, et al 1999)

Pengidentifikasi miskonsepsi dilakukan dengan menghitung persentase siswa yang mengalami miskonsepsi. Perhitungan persentase tersebut diperoleh dari :

$\%$ Mis $=\frac{\text { Jumlah siswa yang mengalami miskonsepsi }}{\text { Jumlah total siswa }} \times 100 \%$

\section{2) Analisis Pergeseran Konsepsi}

Pola pergeseran miskonsepsi siswa dianalisis berdasarkan jawaban siswa yang dilengkapi dengan tingkat keyakinan CRI pada tes awal dan tes akhir, dari hasil tes tersebut akan dihitung seberapa besar persentase siswa menebak, tidak tahu konsep, miskonsepsi, dan tahu akan konsep yang di teskan.

3) Analisis Minimalisasi Miskonsepsi

Analisis miskonsepsi siswa diperoleh dari hasil tes identifikasi miskonsepsi yang dilengkapi dengan CRI pada saat pre tes dan pos tes. seberapa besar penurunan miskonsepsi yang dialami siswa. Hasil tes tersebut akan dihitung seberapa besar persentase penurunan miskonsepsi yang dialami siswa.

\section{HASIL PENELITIAN DAN DISKUSI}

A. Validasi perangkat Pembelajaran

1. Hasil Validasi RPP

RPP yang dikembangkan memiliki kategori sangat valid, dengan percentage of agreement antar validator sebesar 95,49\%.

2. Hasil Validasi Buku Ajar Siswa

BAS yang dikembangkan memiliki kategori valid, dengan percentage of agreement antar validator sebesar $96,30 \%$.
3. Hasil Validasi Lembar Kegiatan Siswa

LKS yang dikembangkan memiliki kategori valid dengan percentage of agreement antar validator sebesar $98,70 \%$.

4. Hasil Validasi Tes Identifikasi Miskonsepsi

Hasil validasi instrument tes identifikasi miskonsepsi dengan percentage of agreement antar validator sebesar $91,05 \%$.

B. Data Hasil Ujicoba

1. Analisis Keterlaksanaan RPP

Analisis data hasil pengamatan keterlaksanaan pembelajaran diketahui bahwa persentase keterlaksanaan secara keseluruhan pada ke empat pertemuan menunjukkan Rata-rata kecocokan pengamat (Percentage of agreement) sebesar 97,56\% dengan kategori sangat baik (Borich, 1994). Hasil penilaian keterlaksanaan pembelajaran disajikan dalam bentuk Gambar 1.

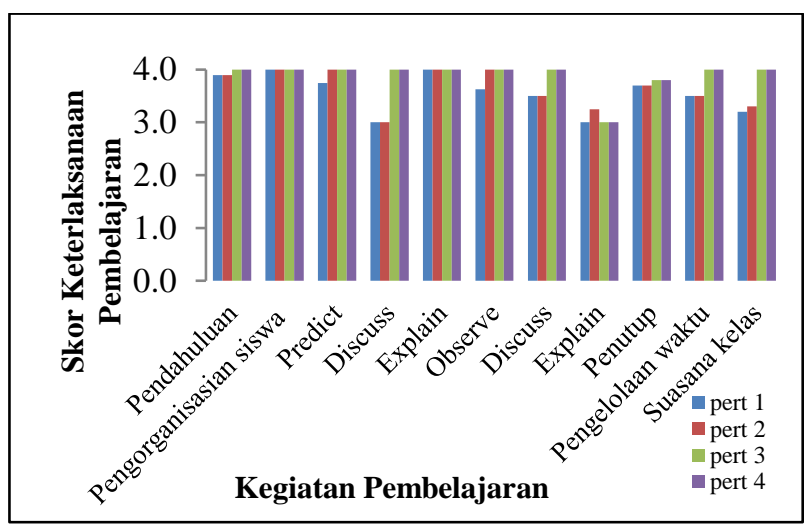

Gambar 1 Diagram Pengamatan Keterlaksanaan RPP

2. Analisis Aktivitas Siswa

Data aktivitas siswa diperoleh melalui pengamatan yang dilakukan oleh dua orang pengamat selama kegiatan pembelajaran berlangsung. Hasil pengamatan aktivitas siswa yang diperoleh selama empat kali pertemuan dapat dilihat pada Gambar 2 berikut:

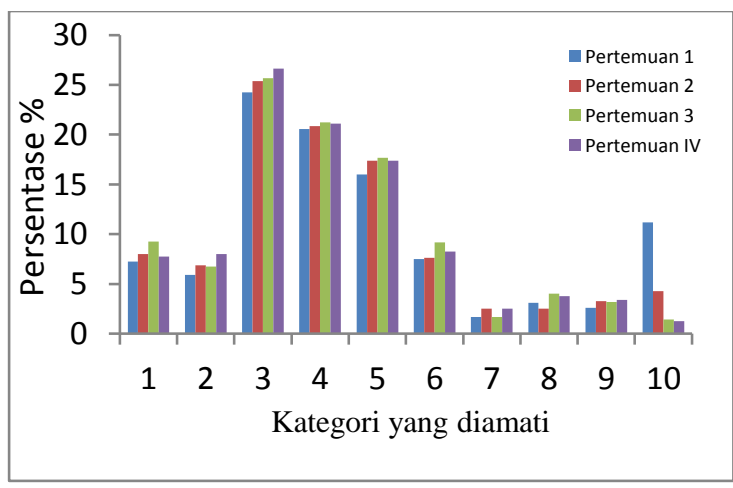

Gambar 2 Diagram Pengamatan Aktivitas Siswa 
Keterangan Aktivitas :

1. Mengamati apa yang ditampilkan oleh guru.

2. Melakukan prediksi

3. Melakukan kegiatan pengamatan

4. Menuliskan hasil pengamatan

5. Melakukan disksusi dalam kelompok

6. Mencari dan membaca informasi pada buku ajar yang sesuai dengan pengamatan

7. Mempersentasikan hasil diskusi dan pengamatan

8. Menanggapi penyajian kelompok lain

9. Membuat kesimpulan

10. Aktivitas tidak relevan seperti : mengganggu teman yang lain, keluar masuk kelas, tidak duduk dalam kelompoknya, dan aktivitas lainnya yang mengganggu proses pembelajaran.

Dari diagram tersebut diketahui bahwa aktivitas yang menunjang proses pembelajaran sebagian besar persentasenya mengalami kenaikan setiap kali pertemuan. Sedangkan aktivitas yang tidak relevan mengalami penurunan. Hal ini menunjukkan bahwa strategi PDEODE meningkatkan aktivitas positif siswa dalam proses pembelajaran.

\section{Kendala dalam pembelajaran}

Proses pembelajaran dengan menggunakan strategi PDEODE ini, tidak sepenuhnya berjalan mulus dan tanpa kendala, pada pelaksanaan pembelajaran ditemukan adanya beberapa hambatan dan kendala yang dapat mengganggu proses pembelajaran. Kendala selama proses pembelajaran tersebut dapat dilihat pada Tabel 4 berikut.

Tabel 4 Kendala Selama Proses Pembelajaran

\begin{tabular}{|c|c|}
\hline Jenis Kendala & Solusi \\
\hline $\begin{array}{l}\text { 1. Masih banyak siswa } \\
\text { yang tidak membaca } \\
\text { prosedur kerja yang ada } \\
\text { dalam LKS, sehingga } \\
\text { dalam melakukan } \\
\text { kegiatan masih banyak } \\
\text { melibatkan guru }\end{array}$ & 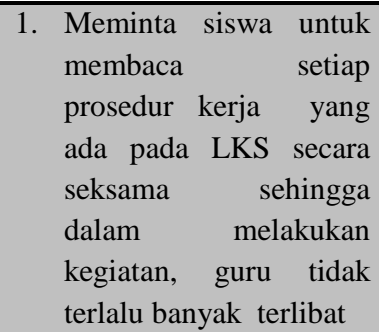 \\
\hline $\begin{array}{lr}\text { 2. Siswa } & \text { kurang } \\
\text { memanfaatkan } & \text { buku } \\
\text { ajar siswa } & \text { sebagai } \\
\text { sumber belajarar } & \end{array}$ & $\begin{array}{llr}\text { 2. Mengingatkan } & \text { siswa } \\
\text { untuk membaca } & \text { buku } \\
\text { ajar siswa } & \text { agar } \\
\text { memudahkan } & \text { siswa } \\
\text { dalam } \quad \text { mengerjakan } \\
\text { LKS. }\end{array}$ \\
\hline $\begin{array}{l}\text { 3. Masih kurangnya rasa } \\
\text { percaya diri siswa } \\
\text { untuk } \\
\text { mempresentasikan hasil } \\
\text { kegiatan kelompoknya } \\
\text { di hadapan teman- }\end{array}$ & $\begin{array}{l}\text { 3. } \begin{array}{l}\text { Memberikan reward } \\
\text { (penghargaan) }\end{array} \\
\text { kepada } \\
\text { siswa yang mau } \\
\text { mempresentasikan hasil } \\
\text { kegiatannya secara } \\
\text { sukarela. }\end{array}$ \\
\hline
\end{tabular}

\begin{tabular}{|c|c|c|}
\hline & Jenis Kendala & Solusi \\
\hline \multicolumn{3}{|c|}{ temannya yang lain } \\
\hline \multirow[t]{5}{*}{4.} & Alokasi & mengingatkan \\
\hline & dibutuhkan siswa untuk & siswa untuk \\
\hline & menyelesaikan & menggunakan \\
\hline & 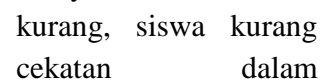 & $\begin{array}{l}\text { sebaik mungkin agar } \\
\text { tepat pada waktunya. }\end{array}$ \\
\hline & melaksanakan LKS & \\
\hline
\end{tabular}

4. Hasil Identifikasi Miskonsepsi Siswa

Hasil tes identifikasi awal siswa dianalisis secara individu dan kelompok sesuai dengan ketentuan CRI untuk membedakan siswa yang menebak, tidak tahu konsep, tahu konsep, dan miskonsepsi.

Identifikasi miskonsepsi siswa bertujuan untuk mengetahui persentase miskonsepsi siswa pada masing-masing konsep. Persentase identifikasi miskonsepsi siswa dapat ditunjukkan pada Gambar 3 (Pre test) Gambar 4 (Post test) berikut.

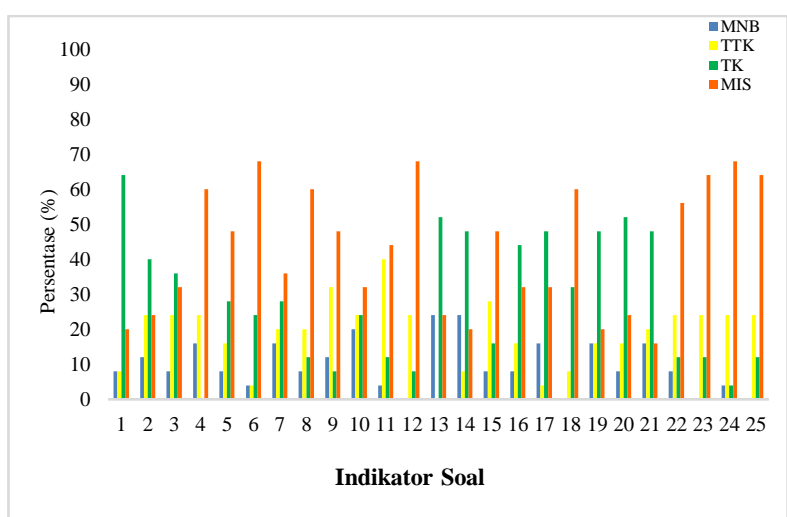

Gambar 3. Diagram Persentase Siswa Menebak (MNB), Tidak Tahu Konsep (TTK), Tahu Konsep (TK), dan Miskonsepsi (MIS) pada Pre Test.

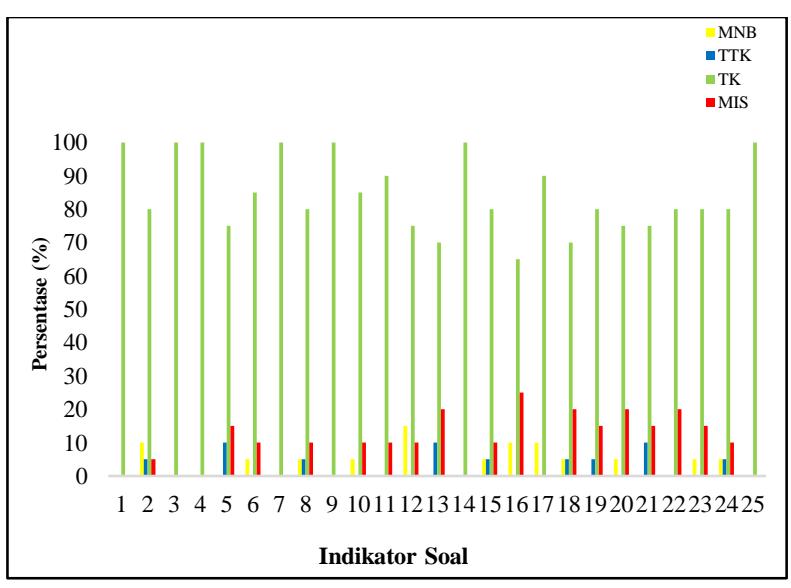

Gambar 4. Diagram Persentase Siswa Menebak (MNB), Tidak Tahu Konsep (TTK), Tahu Konsep (TK), dan Miskonsepsi (MIS) pada Post Test. 
Miskonsepsi yang dialami siswa diidentifikasi dengan menggunakan tingkat keyakinan Certainty of Response (CRI) dari Hasan, et al (1999) dan teknik CRI yang dimodifikasi oleh Hakim, et al (2012), berupa kombinasi soal pilihan ganda dengan alasan terbuka, dan indeks keyakinan siswa dalam menjawab. CRI merupakan teknik dengan pengukuran tingkat keyakinan/kepastian responden dalam menjawab setiap pertanyaan yang diberikan. Identifikasi miskonsepsi siswa bertujuan untuk mengetahui persentase miskonsepsi yang dialami siswa pada masing-masing konsep.

Tes identifikasi miskonsepsi yang digunakan terdiri dari 25 soal berupa pilihan ganda yang dilengkapi dengan tingkat keyakinan CRI dan alasan terbuka. Namun terdapat beberapa siswa yang tidak menuliskan alasannya karena berbagai sebab, misalnya hanya jawaban menebak atau menulis alasan yang tidak relevan dengan jawaban yang dipilih. Berdasarkan hasil analisis data siswa diperoleh bahwa terdapat beberapa konsep-konsep pada pokok bahasan struktur dan fungsi tubuh tumbuhan yang mengalami miskonsepsi, seperti jaringan penyusun organ tumbuhan, fungsi organ tumbuhan, perbedaan organ monokotil dan dikotil, dan fungsi organ tumbuhan. Sejalan dengan yang diungkapkan Ibrahim (2012) miskonsepsi adalah ide atau pandangan yang salah tentang konsep yang dimiliki seseorang yang berbeda dengan konsep yang disepakati dan dianggap benar oleh para ahli. Sama halnya dengan yang diungkapkan Ross (2003) bahwa miskonsepsi adalah pemahaman yang berbeda yang tidak sesuai dengan penjelasan ilmiah.

Siswa dikategorikan miskonsepsi apabila menjawab soal salah dengan tingkat keyakinan CRI yang tinggi yaitu $>2,5$ berdasarkan interpretasi CRI. Dari gambar 4 dan 5 menunjukkan bahwa kemampuan siswa dalam menjawab masing-masing soal bervariasi, ada yang hanya menebak, tidak tahu konsep, miskonsepsi, dan tahu konsep pada pretest dan postest.

\section{Penurunan Miskonsepsi}

Penurunan miskonsepsi pada siswa dapat diamati dengan membandingkan persentase jumlah siswa yang mengalami miskonsepsi pada tes awal (pretest) dengan persentase jumlah siswa yang mengalami miskonsepsi pada tes akhir (posttest). Persentase penurunan miskonsepsi siswa pada pretest dan posttest dari miskonsepsi menjadi tahu konsep ditunjukkan pada Tabel 5 berikut ini.

Tabel 5. Persentase Penurunan Miskonsepsi Siswa

\begin{tabular}{|c|c|c|c|c|c|}
\hline \multirow{2}{*}{$\begin{array}{l}\text { No. } \\
\text { Soal }\end{array}$} & \multicolumn{2}{|c|}{ Pretest } & \multicolumn{2}{|c|}{ Posttest } & \multirow{2}{*}{$\begin{array}{c}\text { Penurunan } \\
\text { Miskonsepsi } \\
(\%)\end{array}$} \\
\hline & $\begin{array}{c}\text { Jumlah } \\
\text { siswa } \\
\end{array}$ & $(\%)$ & $\begin{array}{c}\text { Jumlah } \\
\text { Siswa } \\
\end{array}$ & $(\%)$ & \\
\hline 1 & 5 & 20 & 0 & 0 & 20 \\
\hline 2 & 6 & 24 & 1 & 4 & 20 \\
\hline 3 & 8 & 32 & 0 & 0 & 32 \\
\hline 4 & 15 & 60 & 3 & 12 & 48 \\
\hline 5 & 12 & 48 & 3 & 12 & 36 \\
\hline 6 & 17 & 68 & 2 & 8 & 60 \\
\hline 7 & 9 & 36 & 4 & 16 & 20 \\
\hline 8 & 15 & 60 & 4 & 16 & 44 \\
\hline 9 & 12 & 48 & 6 & 24 & 24 \\
\hline 10 & 8 & 32 & 4 & 16 & 16 \\
\hline 11 & 11 & 44 & 8 & 32 & 12 \\
\hline 12 & 17 & 68 & 0 & 0 & 68 \\
\hline 13 & 6 & 24 & 5 & 20 & 4 \\
\hline 14 & 5 & 20 & 3 & 12 & 8 \\
\hline 15 & 12 & 48 & 7 & 28 & 20 \\
\hline 16 & 8 & 32 & 7 & 28 & 4 \\
\hline 17 & 8 & 32 & 3 & 12 & 20 \\
\hline 18 & 15 & 60 & 6 & 24 & 36 \\
\hline 19 & 5 & 20 & 2 & 8 & 12 \\
\hline 20 & 6 & 24 & 3 & 12 & 12 \\
\hline 21 & 8 & 32 & 4 & 16 & 16 \\
\hline 22 & 14 & 56 & 9 & 36 & 20 \\
\hline 23 & 16 & 64 & 5 & 20 & 44 \\
\hline 24 & 17 & 68 & 5 & 20 & 48 \\
\hline 25 & 16 & 64 & 6 & 24 & 40 \\
\hline
\end{tabular}

Data pada Tabel 5 diperoleh bahwa terjadi penurunan miskonsepsi siswa hampir di semua konsep pada pokok bahasan struktur dan fungsi tubuh tumbuhan setelah pembelajaran dengan strategi PDEODE. Penurunan miskonsepsi siswa dapat dikarenakan pembelajaran menggunakan strategi PDEODE menyebabkan terjadinya proses internal dan intensif pada siswa. Menurut Posner et al (dalam Suparno, 2005) bahwa perubahan konsep dalam diri siswa melalui dua tahap yaitu asimilasi dan akomodasi.

Setelah pembelajaran dengan strategi PDEODE masih ditemukan siswa yang tetap mengalami miskonsepsi atau tidak terjadi pergeseran konsep yaitu pada soal nomor $9,10,11,13,14,15,16,18,20,21$, 23 , 24, dan 25. Hal ini dimungkinkan bahwa siswa tidak fokus pada saat pembelajaran mengenai konsep tersebut atau kemungkinan siswa tetap mempertahankan pengetahuannya yang keliru tentang konsep tersebut, sehingga miskonsepsi yang dialami saat pretes terulang kembali saat posttes. Menurut 
Ibrahim (2012) biasanya miskonsepsi ini bersifat resisten dan persisten. Penyebab dari resistennya sebuah miskonsepsi karena setiap orang membangun pengetahuan persis dengan pengalamannya. Sekali kita telah membangun pengetahuan, maka tidak mudah untuk memberi tahu bahwa hal tersebut salah dengan jalan hanya memberi tahu untuk mengubah miskonsepsi itu. Sejumlah miskonsepsi sangatlah bersifat resisten, walaupun telah diusahakan untuk menyangkalnya dengan penalaran yang logis dengan menunjukkan perbedaannya dengan pengamatanpengamatan sebenarnya, yang diperoleh dari peragaan dan percobaan yang dirancang khusus untuk maksud itu.

Hasil penurunan miskonsepsi yang dianalisis dengan CRI menunjukkan terjadi penurunan miskonsepsi yang dialami siswa setelah pembelajaran dengan strategi PDEODE. Hal ini didukung oleh hasil penelitian oleh (Costu, 2008; Costu, 2012; Gustiani, 2013, Sa'idah dan Suyono, 2012; Solichah, 2014; Sugiarti, 2015; dan Tabitha, 2012) yang menyimpulkan bahwa strategi PDEODE mampu menurunkan miskonsepsi siswa.

\section{Respon Siswa}

Respon siswa dilakukan setelah serangkaian proses pembelajaran dari pertemuan pertama hingga pertemuan ketiga selesai dilaksanakan dengan memberikan angket kepada 25 siswa Hasil analisis respon siswa terhadap perangkat pembelajaran dan pelaksanaan pembelajaran dengan strategi PDEODE untuk meminimalisasi miskonsepsi siswa pada materi struktur dan fungsi tubuh tumbuhan diperoleh $92,4 \%$ siswa merespon positif.

\section{SIMPULAN}

\section{A. Simpulan}

Berdasarkan hasil penelitian dan pembahasan, dapat disimpulkan bahwa perangkat pembelajaran IPA berbasis strategi PDEODE pada materi struktur dan fungsi jaringan tumbuhan layak digunakan karena telah memenuhi kriteria valid, praktis, dan efektif untuk meminimalisasi miskonsepsi IPA siswa SMP.

\section{B. Saran}

Berdasarkan hasil penelitian yang telah dilakukan dapat diberikan beberapa saran sebagai berikut:

1. Setiap guru harus secara rutin mengidentifikasi miskonsepsi yang terjadi baik itu pada siswa maupun sumber belajar yang digunakan agar materi yang akan disampaikan tidak menimbulkan miskonsepsi baru pada siswa.
2. Miskonsepsi IPA yang terjadi pada siswa dapat diminimalisasi apabila guru mampu menentukan strategi pembelajaran yang tepat misalnya strategi PDEODE.

3. Guru harus lebih sering membawa siswa ke arah berfikir lateral, sehingga siswa dapat membuat jawaban atau contoh sendiri atas fenomenafenomena yang ditemuinya dan tidak selalu mengandalkan jawaban yang ada di buku.

\section{DAFTAR PUSTAKA}

Awi, M.Darwis, Sukarna. (2009). Pengembangan Model Pembelajaran Konstruktivistik dalam Matematika yang Melibatkan Scaffolding Metakognitif. Laporan Penelitian Hibah Bersaing. Makassar: Universitas Negeri Makassar.

Borich, G. D. (1994). Observation Skills for Effective Teaching. New York: McMillan Publishing Company.

Costu, B. (2008). "Learning Science Trough the PDEODE Teaching Strategy: Helping Students Make Of Everyday Situations". Eurasia Journal of Mathemtahics, Science and Technology Education. 4(1): 3-9.

Departemen Pendidikan Nasional. (2003). UndangUndang RI tentang Sistem Pendidikan Nasional. Jakarta: Depdiknas.

Gustiani, I. (2013). Perubahan Koseptual dan Akusisi Keterampilan Proses Sains Siswa pada Konsep Pemisahan Campuran melalui Metode Predict Discuss Explain Observe Discuss Explain (PDEODE). Skripsi. Bandung: Jurusan IPA FMIPA UPI.

Hakim, A, Liliasari, dan Kadarohman. (2009). Student Concept understanding of Natural Product Chemistry in Primary and Secondary Metabolist Using the Data Collecting technique of Modified CRI. International Journal of Educattional Science, Volume 4, Nomor 3, Hal: 544-553

Hasan, S., Bagayoko, D., and Kelly, E. L. (1999). "Misconception and The Certainty of Response Index". Journal of Physics Education. Vol. 34, No. 5.

Ibrahim, M. (2012). Seri Pembelajaran Inovatif Konsep, Miskonsepsi, dan Cara Pembelajarannya. Surabaya: Unesa University Press.

Ibrahim, M., dan Wahyusukartiningsih. (2014). Model Pembelajaran Inovatif melalui Pemaknaan. Surabaya: Unesa University Press.

Kearney, Matthew. (2001). Student and Teacher Perceptions of the Use of Multimedia Supported Predict-Discuss-Explain Tasks to Probe Undestanding. Journal. p. 589-615. 
Niaz, Mansoor. (2012). Investigating The Effectiveness of a POE-Based Teaching Activity on Student Understanding of Condensation. Journal. p. 47-67.

Riduwan. 2012. Skala Pengukuran Variabel-Variabel Penelitian. Bandung: Alfabeta.

Ross, Keith. (2003). Alternative Framework and Misconsecption in Primary Science. Gordon Guest, UWE, Bristol.

Sa'idah G \& Suyono. (2012). Penerapan Strategi Pembelajaran PDEODE (Predict, Discuss, Explain, Observe, Discuss, Explain) untuk Mereduksi Miskonsepsi Siswa pada Materi Pokok Hidrolisis Garam di SMA Negeri 2 Bojonegoro. Prosiding Seminar Nasional Kimia Unesa 2012. Jurusan Kimia FMIPA UNESA.

Sekartini. (2013). Pengaruh Model Pembelajaran Predict Discuss Explain Observe Discuss Explain (PDEODE) terhadap Pemahaman Konsep IPA Siswa Kelas IV SD Gugus XII Kecamatan
Buleleng.

http://ejournal.undiksha.ac.id/index.php/JJPG SD/article/viewFile/682/556. Diakses tanggal 23 Maret 2016

Solichah I, Tukiran \& Hasan S. (2014). Penerapan Strategi Pembelajaran PDEODE untuk Mereduksi Miskonsepsi Siswa. Jurnal Pendididkan Sains e-Pensa 2 (2): 308-316.

Suparno, P. (2005). Miskonsepsi dan Perubahan Konsep dalam Pendidikan Fisika. Jakarta : PT Grasindo.

Suyati \& Pukan. (2015). Pengembangan Lembar Kgiatan Siswa Berbasis PDEODE pada Materi Sistem Pencernaan Manusia. Unnes Journal of Biology Education 4 (1): 45-52.

Thiagaradjan, S. D. S, Semmel \& M. I, Semmel. (1974). Instructional Development for Teacher Center of Expectional Children. Minepolish: Indiana University.

Trianto. (2009). Mendesain Model Pembelajaran Inovatif Progresif. Jakarta: Kencana Prenada Media Group. 